\title{
Comparison of procedures to evaluate the pathogenicity of Ceratocystis fimbriata sensu lato isolates from Eucalyptus in South Africa
}

\author{
M. van Wyk ${ }^{1}$, R. N. Heath ${ }^{1}$, M. Tarigan ${ }^{2}$, M. Vermeulen ${ }^{2}$ and M. J. Wingfield $^{1}$
}

(1) Department of Genetics, Tree Protection Co-operative Programme (TPCP), Forestry and Agricultural Biotechnology Institute (FABI), University of Pretoria, Pretoria 0002, South Africa.

(2) Department of Microbiology and Plant Pathology, Tree Protection Co-operative Programme (TPCP), Forestry and Agricultural Biotechnology Institute (FABI), University of Pretoria, Pretoria 0002, South Africa.

M. van Wyk

Email: marelize.vanwyk@fabi.up.ac.za

\begin{abstract}
Ceratocystis fimbriata sensu lato (s.l.) is an important pathogen of Eucalyptus. Pathogenicity of isolates has typically been evaluated by inoculating seedlings under greenhouse conditions. It is, however, not clear how accurately this reflects pathogenicity under field conditions. In this study, five techniques to potentially screen $C$. fimbriata isolates for their relative pathogenicity to Eucalyptus were compared. These included: in vitro growth comparisons on artificial media; inoculations on apples; inoculation on Eucalyptus seedlings in a greenhouse; inoculations on Eucalyptus bolts freshly cut from stems of young trees; and field inoculations on young trees. Eight isolates of C. fimbriata s.l. collected from various areas in South Africa were used. There was considerable variation in growth in culture and aggressiveness of the eight isolates. Field inoculations on young trees were best correlated with inoculations of bolts $(r=0.76)$. Lower correlation coefficients were obtained with seedlings $(\mathrm{r}=0.59)$, apple inoculations $(\mathrm{r}=0.56)$, and in vitro colony growth $(\mathrm{r}=0.42)$. Inoculation of bolts provides a rapid and reliable method to screen isolates of C. fimbriata s.l. for pathogenicity to Eucalyptus.
\end{abstract}

\section{Introduction}

Species in the Ceratocystis fimbriata sensu lato species complex include pathogens of a large number of woody and some herbaceous plants (Kile 1993). Symptoms associated with these fungi include vascular staining, cankers and vascular wilt of woody hosts. Some species threaten the productivity of fruit tree crops such as coffee (Coffea spp.) (Marin et al. 2003), cacao (Theobroma cacao) (Engelbrecht and Harrington 2005) and mangoes (Mangifera indica) (Al Adawi et al. 2006, van Wyk et al. 2007), while others are important pathogens of species used to establish commercial forest plantations such as Eucalyptus (Roux et al. 2000).

During the course of the last decade, reports of infections and disease of plantation-grown Eucalyptus trees, caused by fungi in the C. fimbriata s.l. species complex, a wound infecting pathogen, have increased in number. In Brazil (Laia et al. 2000), Republic of Congo (Roux et al. 2000), Uganda (Roux et al. 2001) and Uruguay (Barnes et al. 2003), C. fimbriata s.l. has been reported to result in the rapid wilt and death of Eucalyptus trees. In South Africa, C. fimbriata s.l. has been isolated from wounded Eucalyptus trees although disease symptoms resulting from natural 
infection have not been observed (Roux et al. 2004).

Pathogenicity tests provide an important step in the process of determining whether fungi, including Ceratocystis spp., have the capacity to cause disease on trees from which they have been isolated (Fulbright 1984, Agrios 1994, Heath et al. 2009). Ideally, inoculations are made on healthy trees of the same species as those from which the pathogen was originally isolated, but this is a destructive process that is typically costly and time consuming because trees often need to be reared from seed or cuttings and they are relatively slow growing. Examples of techniques used for pathogenicity tests with tree pathogens include inoculation of branches or stems with agar plugs (Fulbright 1984, Enebak et al. 1994) or gauze (Conradie et al. 1992) on which the fungus has been cultured, or by injecting spore suspensions into artificially made wounds (Brasier and Webber 1987, Chongo and Gossen 2001). Tests are either conducted under controlled conditions in a greenhouse, or under field conditions, depending on the availability of trees and the origin of the fungus to be tested.

A number of economic and environmental factors influence the success of artificial inoculation experiments. Results can vary depending on different levels of host resistance, climatic conditions as well as size and age of the host (Kim et al. 1989, Conradie et al. 1992, Chongo and Gossen 2001). Season, however, does not have a significant effect on infection by Ceratocystis wilt of Acacia (Heath et al. 2009). Pathogenicity tests performed under field conditions most closely resemble natural conditions but they are time consuming and expensive due to the need for destructive sampling, and large experimental plots. It is also not possible to inoculate non-native pathogens under field conditions and such tests must occur on model systems in quarantine greenhouses. Model systems for pathogenicity tests frequently use seedlings in greenhouses but these can result in low levels of correlation between field results and greenhouse experiments (Conradie et al. 1992, van der Westhuizen et al. 1992, Hong and Hwang 1998). Other characteristics, for example considering rate of growth in culture or inoculations on fruit such as apples (Fulbright 1984, Enebak et al. 1994, de Lange et al. 1998) have also been used to reflect pathogenicity of fungi, but these are valuable only if they are known to correlate with results from field tests.

In this study, five methods to predict the pathogenicity of C. fimbriata s.l. to Eucalyptus were compared. These included: (1) in vitro growth comparisons on artificial media, (2) inoculations on apples, (3) inoculations on Eucalyptus seedlings in a greenhouse, (4) inoculations on Eucalyptus bolts freshly cut from stems of young trees, and (5) field inoculations on young trees. Colony growth rate in culture and the results of inoculations on apples were the two methods first considered. Results of these tests were compared with inoculations on seedlings in the greenhouse, on established trees in the field and on Eucalyptus bolts that had been freshly cut from the stems of young trees. The hypotheses that isolates growing most rapidly in culture would also be the more aggressive in pathogenicity tests and that seedling inoculations in greenhouses would not correlate well with field trials were tested.

\section{Materials and methods}

\section{Fungal isolates}

Eight isolates of C. fimbriata s.l. (CMW9998, CMW10139, CMW10760, CMW11536, CMW11537, CMW11543, CMW12670, CMW13028) collected from Eucalyptus trees from various geographical areas in South Africa, were used in this study. All the isolates were obtained from artificially wounded trees and they are maintained in the culture collection (CMW) of the Forestry and Agriculture Biotechnology Institute (FABI), University of Pretoria, South Africa. 


\section{In vitro colony growth}

In vitro colony growth of the $C$. fimbriata s.l. isolates was determined on $2 \%$ malt extract agar (MEA) plates. These were inoculated by placing a $4 \mathrm{~mm}$ plug of mycelium taken from a pure culture (7-10 d old) at the centres of $90 \mathrm{~mm}$ diameter Petri dishes. Each isolate was represented by preparing five plates for each temperature to be tested. Cultures were incubated in the dark at $20{ }^{\circ} \mathrm{C}$, $25^{\circ} \mathrm{C}$ and $30^{\circ} \mathrm{C}$, respectively. The three temperatures were selected because they fall within the optimum temperature range for growth of the test fungus ( $\mathrm{MvW}$ unpublished data). Seven days after inoculation, two diameter measurements were made perpendicular to each other and the averages were calculated. The experiment was repeated once.

\section{Apple inoculations}

Granny Smith apples (de Lange et al. 1998) were used to screen the same isolates of $C$. fimbriata s.l. used in the agar growth tests. Fresh apples were used and apples with bruises were excluded. The apples were washed in soapy water, rinsed and dried, and then surface disinfected with $70 \%$ ethanol.

Isolates of the test fungi were grown on $2 \%$ MEA supplemented with streptomycin sulphate $(0.001$ $\mathrm{g}^{-1}$, Sigma, Steinheim, Germany) for one week. Two wounds, $4 \mathrm{~mm}$ deep and $4 \mathrm{~mm}$ in diameter, were made on opposite sides of the apples, using a cork borer. Mycelial plugs of the same size were taken from the edges of actively growing cultures, and placed into the wounds on one side of each apple, with the mycelium facing inwards. Sterile MEA plugs were placed in the wounds on the opposite sides of each apple to serve as negative controls. Wounds were sealed with laboratory film (Parafilm ' $\mathrm{M}$ ', American National $\mathrm{Can}^{\mathrm{TM}}$, Chicago) to protect the inoculated fungus and apples from desiccation.

Twenty apples were inoculated for each test isolate. The inoculated apples were incubated in a greenhouse, at $25^{\circ} \mathrm{C}$ and subjected to day/night conditions (c. $13 \mathrm{~h}$ daylight/c. $11 \mathrm{~h}$ darkness). Lesions associated with the inoculations were evaluated after $7 \mathrm{~d}$. Two measurements of the diameter of the lesions around each wound were taken perpendicular to each other on the outer surfaces of the inoculated apples. The depths of the lesions were also measured. The experiment was repeated once and the data for the two experiments were pooled. Inoculated fungi were reisolated from the lesions to show that the inoculated fungus was responsible for the lesions on the apples.

\section{Greenhouse inoculations of seedlings}

One-year-old seedlings, having approximately $10 \mathrm{~mm}$ diameter stems, of an E. grandis clone (ZG14) known to be susceptible to $C$. fimbriata s.l. (Roux et al. 2004) were maintained under greenhouse conditions for a two-week acclimatisation period prior to the commencement of the inoculation experiment. The seedlings were planted in 51 pots with standard nursery potting soil. The greenhouse was subjected to natural day/night conditions and a temperature of approximately $25{ }^{\circ} \mathrm{C}$ was maintained. Twenty trees were inoculated with seven-day-old cultures of each of the eight $C$. fimbriata s.l. isolates used in all the tests. An additional 10 seedlings were inoculated with sterile MEA plugs to serve as controls. Wounds were made on the stems of trees approximately 100 $\mathrm{mm}$ from soil level, using a $4 \mathrm{~mm}$ diameter cork borer to expose the cambium. Plugs of mycelium were placed into the wounds, with the mycelium facing the cambium and inoculation points were sealed with laboratory film.

Lesion lengths associated with the inoculations on the stems of trees were measured on the inside of the bark after six weeks. The experiment was repeated once. Isolations were made from resultant 
lesions to show that they had resulted from the inoculated fungi.

\section{Bolt inoculations}

Six-year-old E. grandis trees of a single clone (ZG14) growing on the experimental farm of the University of Pretoria were felled. Three to four, $40 \mathrm{~cm}$ long bolts were cut from the stems of each tree as soon as possible after felling and on the same day that the inoculations were made. The sections were cut in such a way as to ensure the lowest possible number of branches on the bolts. Where branch stubs were present, these as well as the cut ends of the bolts were sealed with paraffin wax, to prevent desiccation.

Each bolt was randomly selected and inoculated with one of the eight $C$. fimbriata s.l. isolates used in all experiments, with 20 bolts per isolate. An additional 20 bolts were inoculated with sterile MEA plugs to serve as negative controls. Inoculations were made at approximately the mid-point of the bolts, with two inoculation points on each bolt at opposite sides from each other. One inoculation wound on each bolt was treated with a $7 \mathrm{~mm}$ disc of agar overgrown with the test fungus (seven days old) and the other wound was treated with a sterile MEA plug. After inoculation, the wounds were covered with masking tape to prevent desiccation. Inoculated bolts were maintained at $25{ }^{\circ} \mathrm{C}$ under day/night conditions for four weeks in a greenhouse, after which lesion lengths in the cambium were measured. Isolations were made from the lesions to ensure that the inoculated fungus was the same as that associated with the lesion. The experiment was repeated once and the data pooled.

\section{Field inoculations}

Healthy six-year-old E. grandis trees (clone ZG14) were inoculated under field conditions in KwaMbonambi, KwaZulu-Natal. The wounds were made with a $7 \mathrm{~mm}$ cork-borer on the bark to expose the cambium of the tree. Trees were inoculated approximately $1 \mathrm{~m}$ above the soil surface by inserting a $7 \mathrm{~mm}$ disc of agar overgrown with the test fungus (seven days old) into the inoculation wound. After inoculation, the wounds were covered with masking tape to prevent desiccation. Each of the eight previously mentioned isolates was inoculated onto the stems of 20 trees. The same number of trees was also inoculated with sterile MEA plugs to serve as negative controls. The lengths of lesions that formed under the bark on the cambium were measured after six weeks. Reisolations were made from the lesions to confirm Koch's postulates. The experiment was repeated once.

\section{Statistical analyses}

General linear model (GLM) processing was performed on all the data generated from this study using SAS 8.2 (SAS 2001) to determine significant differences in growth or lesion length between isolates in each treatment. The data were then subjected to a univariate procedure. The data for each replicate of each technique were pooled for analyses. Pearson correlation coefficients (PCC) were calculated to determine positive or negative correlation between the various techniques using SAS 8.2 (SAS 2001) and to determine the most accurate evaluation method to test the pathogenicity of C. fimbriata s.l.

\section{Results}

\section{In vitro colony growth}

The eight $C$. fimbriata s.l. isolates used in this study could be divided into two groups based on statistical analyses of colony growth at $25{ }^{\circ} \mathrm{C}$. Twenty-five degrees Celsius was selected because 
optimum growth was observed at this temperature for all isolates tested. Four isolates (CMW9998, CMW10760, CMW11537, CMW11543) were relatively slow growing and four (CMW10139, CMW11536, CMW12670, CMW13028) grew more rapidly. Isolate CMW9998 had the slowest growth, reaching $19.3 \mathrm{~mm}$ diameter $(\mathrm{SD}=2.3 \mathrm{~mm}$ ) in $7 \mathrm{~d}$. In contrast, isolate CMW12670 grew most rapidly, reaching $45.7 \mathrm{~mm}$ in diameter $(\mathrm{SD}=1.8 \mathrm{~mm})$ in $7 \mathrm{~d}$, which was significantly different from all other isolates (Table 1). Growth of isolates CMW10760, CMW11537 and CMW11543 did not differ significantly from each other, but differed from that of all other isolates. The same was true for isolates CMW11536, CMW13028 and CMW10139 (Table 1).

Table 1. Growth in culture and lesions produced for eight isolates of Ceratocystis fimbriata s.l. isolates for inoculations on apples, seedlings, established trees and bolts of Eucalyptus grandis clone ZG14. Averages calculated over combined data (40 individuals) for each treatment. Standard deviations are indicated in brackets. Values in columns followed by the same superscript letter are not statistically different from each other based on $95 \%$ confidence limit.

\begin{tabular}{|c|c|c|c|c|c|}
\hline \multirow[b]{2}{*}{ Isolate } & \multicolumn{5}{|c|}{ Treatment and average lesion lengths } \\
\hline & in vivo growth (mm) & Apple inoculations (mm) & $\begin{array}{l}\text { Seedling inoculations } \\
\qquad(\mathrm{mm})\end{array}$ & $\begin{array}{l}\text { Bolt inoculations } \\
(\mathrm{cm})\end{array}$ & $\begin{array}{l}\text { Field inoculations } \\
(\mathrm{cm})\end{array}$ \\
\hline Control & - & $4.0^{3}(0)$ & $4.0^{\mathrm{a}}(0)$ & $0.7^{3}(0)$ & $0.7^{3}(0)$ \\
\hline CMW9998 & $19.3^{\circ}(2.3)$ & $19.1^{\circ}(1.5)$ & $34.4^{\mathrm{cc}}(6.2)$ & $26.4^{\circ}(8.1)$ & $52.9^{\circ c}(8.4)$ \\
\hline CMW10139 & $37.9^{\circ}(1.2)$ & $12.5^{\circ}(1.2)$ & $16.1^{d}(4.6)$ & $33.5^{\circ}(3.2)$ & $56.9^{\circ}(4.6)$ \\
\hline CMW10760 & $25.8^{d}(3.4)$ & $16.3^{\text {de }}(2.5)$ & $29.1^{\mathrm{bc}}(9.5)$ & $25.1^{\circ}(8.8)$ & $42.4^{\circ}(6.9)$ \\
\hline CMW11536 & $32.0^{\circ}(2.7)$ & $18.8^{\circ}(3.7)$ & $34.0^{\infty c}(6.9)$ & $29.8^{\circ}(7.2)$ & $103.4^{\circ}(12.8)$ \\
\hline CMW11537 & $25.0^{d}(5)$ & $16.8^{\text {de }}(2.8)$ & $45.2^{e}(7.3)$ & $35.0^{\circ}(7.5)$ & $62.9^{\circ}(8.2)$ \\
\hline CMW11543 & $24.2^{d}(3.9)$ & $18.6^{\circ}(3.8)$ & $37.5^{\circ}(8.4)$ & $35.0^{\circ}(7.8)$ & $66.5^{\circ}(5.1)$ \\
\hline CMW12670 & $45.7^{e}(1.8)$ & $15.8^{d}(3)$ & $37.6^{\circ}(8.3)$ & $23.5^{\circ}(5.9)$ & $43.1^{\circ}(8.7)$ \\
\hline CMW13028 & $33.1^{\circ}(3.9)$ & $17.8^{\circ 0}(2.6)$ & $26.5^{b}(2.3)$ & $21.0^{\circ}(4.9)$ & $41.0^{\circ}(7.3)$ \\
\hline
\end{tabular}

\section{Apple inoculations}

All eight $C$. fimbriata s.l. isolates produced lesions on apples, which differed significantly $(\mathrm{P}<$ 0.0001) from the control inoculations where no lesions developed. Statistical differences were observed between various isolates tested (Table 1). Isolate CMW10139 produced the smallest lesions $(\mathrm{x}=12.5 \mathrm{~mm}$; $\mathrm{SD}=1.2 \mathrm{~mm})$ while CMW9998 produced the largest lesions $(\mathrm{x}=19.1 \mathrm{~mm}$; $\mathrm{SD}=1.5 \mathrm{~mm})$. The lesions associated with inoculation with these isolates differed significantly from each other. Ceratocystis fimbriata s.l. was successfully reisolated from the lesions associated with the inoculations.

\section{Greenhouse inoculations of seedlings}

All C. fimbriata s.l. isolates produced lesions on the inoculated seedlings which differed significantly $(\mathrm{P}<0.0001)$ from the control inoculations, where small lesions were observed. Isolate CMW10139 produced the smallest lesions $(\mathrm{x}=16.1 \mathrm{~mm}$; $\mathrm{SD}=4.6 \mathrm{~mm})$ and was significantly different $(\mathrm{P}<0.0001)$ from all other isolates (Table 1). Isolate CMW11537 produced the longest lesions $(\mathrm{x}=45.2 \mathrm{~mm}$; $\mathrm{SD}=7.3 \mathrm{~mm})$ and was significantly different from those produced by all other isolates except isolates CMW12670 and CMW11543 (Table 1). Isolates CMW9998, CMW10760, CMW13028 and CMW11536 produced lesions that were not significantly different (P $=0.2440$ and $\mathrm{P}=0.3631$, respectively) from each other. Ceratocystis fimbriata s.l. was successfully reisolated from the lesions but not from the control inoculation sites.

\section{Bolt inoculations}

All C. fimbriata s.l. isolates produced lesions on stem bolts that were significantly different $(\mathrm{P}<$ 0.0001 ) from those of the control inoculations, which produced small lesions. Isolate CMW13028 produced the smallest lesions $(\mathrm{x}=21 ; \mathrm{SD}=4.9 \mathrm{~cm})$ and these were statistically different from all other isolates, except CMW9998 $(\mathrm{x}=26.4 \mathrm{~cm} ; \mathrm{SD}=8.1 \mathrm{~cm}), \mathrm{CMW} 10760(\mathrm{x}=25.1 \mathrm{~cm} ; \mathrm{SD}=8.8$ 
$\mathrm{cm})$ and CMW12670 (x = $23.5 \mathrm{~cm} ; \mathrm{SD}=5.9 \mathrm{~cm})($ Table 1). Isolates CMW10139 $(\mathrm{x}=33.5 \mathrm{~cm}$; SD $=3.2 \mathrm{~cm})$, CMW11536 $(\mathrm{x}=29.8 \mathrm{~cm} ; \mathrm{SD}=7.2 \mathrm{~cm}), \mathrm{CMW} 11537(\mathrm{x}=35 \mathrm{~cm} ; \mathrm{SD}=7.5 \mathrm{~cm})$ and CMW11543 $(\mathrm{x}=35 \mathrm{~cm}$; SD $=7.8 \mathrm{~cm})$ did not differ significantly from each other but they did differ from lesions associated with all other isolates. Ceratocystis fimbriata s.l. was successfully reisolated from the lesions but not from the control inoculation points.

\section{Field inoculations}

Lesions, significantly different $(\mathrm{P}<0.0001)$ in size from the controls, were produced on trees by all the $C$. fimbriata s.l. isolates tested. Isolate CMW13028 produced the shortest average lesion length $(\mathrm{x}=41 \mathrm{~cm}$; $\mathrm{SD}=7.3 \mathrm{~cm})$, but was not significantly different from those associated with isolates CMW9998 $(\mathrm{x}=52.85 \mathrm{~cm} ; \mathrm{SD}=8.4 \mathrm{~cm})$, CMW10760 $(\mathrm{x}=42.35 \mathrm{~cm} ; \mathrm{SD}=6.9 \mathrm{~cm})$ and CMW12670 $(\mathrm{x}=43.1 \mathrm{~cm} ; \mathrm{SD}=8.7 \mathrm{~cm})($ Table 1). Isolate CMW11536 produced the longest lesions $(\mathrm{x}=103.4 \mathrm{~cm} ; \mathrm{SD}=12.8 \mathrm{~cm})$, and was significantly different from those produced by all other isolates (Table 1). Ceratocystis fimbriata s.l. was re-isolated from the lesions but not from the control inoculation points.

\section{Correlation between field trials and other treatments}

Calculation of the Pearson correlation coefficient (r), indicating correlation between the field trials and all other treatments, resulted in positive correlation between field trial results and the methods to potentially reflect pathogenicity of isolates (Table 2 ). The correlation values (r) ranged between 0.4164 and 0.7600 . The weakest correlation was observed between the field trial and colony growth $(\mathrm{r}=0.4164)$. The strongest correlation was observed between lesions on trees in the field trial and those emerging from inoculations on bolts $(\mathrm{r}=0.7600)$. The two remaining treatments produced correlation values of approximately $55 \%$ with those of the field trial.

Table 2. Pearson correlation coefficients (r) indicating correlation between the field trials (column 1) and all other treatments (columns $2-5)$. A higher $r$-value indicates a higher correlation $(1=100 \%$ correlation).

\begin{tabular}{lcccc}
\hline Treatment & In vitro colony growth & Apple trial & Seedling trial & Bolt trial \\
\hline Field trial & 0.4164 & 0.55596 & 0.59070 & Field trial \\
\hline
\end{tabular}

\section{Discussion}

The overall goal of this study was to identify a cost- and time-efficient method that might reflect the pathogenicity of C. fimbriata s.l. isolates occurring on Eucalyptus spp. This is especially important because results of field and greenhouse experiments do not always correlate with each other (van der Westhuizen et al. 1992). Importantly, a technique was also sought that would make it possible to evaluate non-native isolates under quarantine greenhouse conditions. The results of the study provided valuable insights into ideal conditions for inoculations, showing that seedlings do not yield results that are consistent with inoculations on mature trees in the field. This study also showed that inoculations on freshly cut bolts gave results that are relatively strongly correlated with field inoculations. These inoculations can be undertaken under quarantine conditions and would be preferable to inoculations on seedlings.

While seedling inoculations provide a firm indication of the ability of a fungus to produce lesions, they are not necessarily the most reliable means to test the pathogenicity of isolates. This could be due to the fact that potted plants can receive subtly different levels of fertilisation, moisture and other treatments. Seedling inoculations and various other model tests have been valuable in testing the pathogenicity of tree-infecting fungi (Basham 1970, Barrows-Broaddus and Dwinell 1985, Wingfield 1986). Although results obtained in this study were similar to those found for other 
canker pathogens, such as Chrysoporthe austroafricana (Conradie et al. 1992, van der Westhuizen et al. 1992), it is important to recognise that the biology of the specific pathogen may influence the results. The response of pathogens could be different on different hosts and the fact that Eucalyptus bolt inoculations gave the best results in this study might not be true for related fungi on other hosts.

A number of studies have evaluated the pathogenicity of fungi using the fastest-growing isolates in culture (Fulbright 1984, Brasier and Webber 1987, Enebak et al. 1994). For example, Brasier and Webber (1987) reported a positive correlation between in vitro growth rate and pathogenicity of Ophiostoma ulmi, although this correlation was not consistent in all their experiments. However, van Heerden (1999), using the Eucalyptus canker pathogen Chrysoporthe austroafricana, found no correlation between colony growth rate and pathogenicity of selected isolates of the pathogen. Results of the present study, using $C$. fimbriata s.l., also showed very low correlation between in vitro growth and lesion size on field-inoculated trees.

Inoculations on apples have been applied to reflect the relative pathogenicity of isolates of fungal pathogens (Fulbright 1984, Enebak et al. 1994, de Lange et al. 1998). Results obtained from the apple inoculation study showed a moderate to weak correlation with the pathogenicity results emerging from field inoculations.

Inoculations on trees maintained in greenhouses often serve as the only test of pathogenicity in reports of new diseases (Basham 1970, Barrows-Broaddus and Dwinell 1985, Wingfield 1986). This is typically because inoculations on large trees are not possible due to lack of sufficient numbers of trees for inoculation, high costs and the fact that trees would often need to be grown specifically for such tests (Ferreira et al. 1977, Alfenas et al. 1983, Krokene and Solheim 1998). While some studies have shown comparable results between seedling and field tests (Alfenas et al. 1983, Krokene and Solheim 1998), the opposite has also been shown (Basham 1970, van der Westhuizen et al. 1992). The present study supports previous findings such as those of van der Westhuizen et al. (1992) that results of greenhouse trials have a moderate to weak correlation with those obtained from field studies. This lack of correlation could be due to the anatomical state of the plants inoculated, the age of the plants used (Kim et al. 1989, Conradie et al. 1992, Hong and Hwang 1998), the environmental conditions under which the seedlings are grown, stress due to variable irrigation (Basham 1970, Biggs and Cline 1986) as well as many other factors. In the case of a vascular wilt pathogen such as $C$. fimbriata s.l., the pathogen typically invades the xylem tissue. In seedlings, this tissue is poorly developed, which could furthermore confound the results.

Inoculating bolts cut from freshly felled six-year-old Eucalyptus trees with C. fimbriata s.l. provided the best correlation with the results of inoculations on standing trees in the field. The use of bolts provided several advantages compared to inoculating trees under field conditions. This method demands less space than that required for a field experiment. Bolt inoculations can also easily be conducted under quarantine conditions where it is easy to destroy material after tests have been conducted.

Results of this study have highlighted some shortcomings associated with techniques that are commonly applied to assess the pathogenicity of forest fungi. They have also provided valuable information for future studies using isolates of C. fimbriata s.l. from Eucalyptus trees. Clearly, inoculations on freshly cut $\operatorname{logs}$ will provide an effective assay to assess pathogenicity or to compare the aggressiveness of C. fimbriata s.l. isolates relatively easily and inexpensively.

\section{Acknowledgements}

The authors thank the National Research Foundation (NRF), the members of the Tree Protection Co-operative Programme (TPCP) and the THRIP initiative of the Department of Trade and Industry 
for funding. We are also grateful to the Experimental Farm Committee of the University of Pretoria for the use of the facilities on the farm. We acknowledge Mr M. van der Linde and Prof $\mathrm{H}$. Groeneveld from the Department of Statistics, University of Pretoria, for their assistance with the statistical analyses. Furthermore, we thank Profs T. Coutinho, B. Slippers and J. Roux and Dr M. Coetzee for their assistance in preparing this manuscript.

\section{References}

Agrios GN. 1994. Plant pathology. New York: Harcourt Academic Press.

Al Adawi AO, Deadman ML, Al Rawahi AK, Al Maqbali YM, Al Jahwari AA, Al Saadi BA, Al Amri IS, Wingfield MJ. 2006. Aetiology and causal agents of mango sudden decline disease in the Sultanate of Oman. European Journal of Plant Pathology 116: 247-254.

Alfenas AC, Jeng R, Hubbes M. 1983. Virulence of Cryphonectria cubensis on Eucalyptus species differing in resistance. European Journal of Plant Pathology 13: 179-205.

Barnes I, Roux J, Wingfield BD, O’Neill MO, Wingfield MJ. 2003. Ceratocystis fimbriata infecting Eucalyptus grandis in Uruguay. Australasian Plant Pathology 32: 361-366.

Barrows-Broaddus J, Dwinell LW. 1985. Branch dieback and cone and seed infection caused by Fusarium moniliforme var. subglutinans in a loblolly pine seed orchard in South Carolina. Phytopathology 75: 1104-1108.

Basham HG. 1970. Wilt of loblolly pine inoculated with blue-stain fungi of the genus Ceratocystis. Phytopathology 60: 750-754.

Biggs AR, Cline RA. 1986. The influence of irrigation on wound response in peach bark. Canadian Journal of Plant Pathology 8: 405-408.

Brasier CM, Webber JF. 1987. Positive correlation between in vitro growth rate and pathogenesis in Ophiostoma ulmi. Plant Pathology 36: 462-466.

Chongo G, Gossen BD. 2001. Effect of plant age on resistance to Ascochyta rabiei in chickpea. Canadian Journal of Plant Pathology 23: 358-363.

Conradie E, Swart WJ, Wingfield MJ. 1992. Susceptibility of Eucalyptus grandis to Cryphonectria cubensis. European Journal of Forest Pathology 22: 312-315.

de Lange WJ, Wingfield BD, Wingfield MJ. 1998. A rapid, apple-based test for the virulence in Cryphonectria cubensis isolates. European Journal of Forest Pathology 28: 409-412.

Enebak SA, MacDonald WL, Hillman BI. 1994. Effect of dsRNA associated with isolates of Cryphonectria parasitica from the Central Appalachians and their relatedness to other dsRNAs from North America and Europe. Phytopathology 84: 528-534.

Engelbrecht CJB, Harrington TC. 2005. Intersterility, morphology and taxonomy of Ceratocystis fimbriata on sweet potato, cacao and sycamore. Mycologia 97: 57-69.

Ferreira FA, Reis MS, Alfenas AC, Hodges CS. 1977. Avaliação da resistencia de Eucalyptus spp. ao cancro causado por Diaporthe cubensis Bruner. Fitopatologia Brasileira 2: 225-241. 
Fulbright DW. 1984. Effect of eliminating dsRNA in hypovirulent Endothia parasitica. Phytopathology 74: 722-724.

Heath RN, Wingfield BD, Wingfield MJ, Meke G, Mbaga A, Roux J. 2009. Ceratocystis species on Acacia mearnsii and Eucalyptus spp. in eastern and southern Africa including six new species. Fungal Diversity 34: 41-68.

Hong JK, Hwang BK. 1998. Influence of inoculum density, wetness duration, plant age, inoculation method and cultivar on pepper plants by Colletotrichum coccodes. Plant Disease 82: 1079-1083.

Kile GA. 1993. Plant diseases caused by species of Ceratocystis sensu stricto and Chalara. In: Wingfield MJ, Seifert KA, Webber JF (eds), Ceratocystis and Ophiostoma: taxonomy, ecology and pathogenicity. St Paul: APS Press. pp 173-183.

Kim YJ, Hwang BK, Park KW. 1989. Expression of age-related resistance in pepper plants infected with Phytophthora capsici. Plant Disease 73: 745-747.

Krokene P, Solheim H. 1998. Assessing the virulence of four bark beetle-associated bluestain fungi using Norway spruce seedlings. Plant Pathology 47: 537-540.

Laia ML, Alfenas AC, Harrington TC. 2000. Isolation, detection in soil, and inoculation of Ceratocystis fimbriata, causal agent of wilting, die-back and canker in Eucalyptus. Fitopatologia Brasileira 25: 384 (abstract only).

Marin M, Castro B, Gaitan A, Preisig O, Wingfield BD, Wingfield MJ. 2003. Relationships of Ceratocystis fimbriata isolates from Colombian coffee-growing regions based on molecular data and pathogenicity. Journal of Phytopathology 151: 395-405.

Roux J, Coutinho TA, Mujuni Byabashaija D, Wingfield MJ. 2001. Diseases of plantation Eucalyptus in Uganda. South African Journal of Science 97: 16-18.

Roux J, van Wyk M, Hatting H, Wingfield MJ. 2004. Ceratocystis species infecting stem wounds on Eucalyptus grandis in South Africa. Plant Pathology 53: 414-421.

Roux J, Wingfield MJ, Bouillet JP, Wingfield BD, Alfenas C. 2000. A serious new wilt disease of Eucalyptus caused by Ceratocystis fimbriata in Central Africa. Forest Pathology 30: 175-184.

SAS Institute. 2001. SAS/STAT user's guide, version 8.2. Cary: SAS Institute, Inc.

van der Westhuizen IP, Wingfield MJ, Swart WJ, Kemp GHJ. 1992. Comparison of the susceptibility of Eucalyptus clones to Cryphonectria cubensis under field and greenhouse conditions. Phytopathology 24: 107.

van Heerden SW. 1999. Pathogenicity and variation amongst South African isolates of Cryphonectria cubensis. MSc thesis, University of Pretoria, South Africa.

van Wyk M, Al Adawi AO, Khan IA, Deadman ML, Al Jahwari A, Wingfield BD, Ploetz R, Wingfield MJ. 2007. Ceratocystis manginecans sp. nov., causal agent of a destructive mango wilt disease in Oman and Pakistan. Fungal Diversity 27: 213-230.

Wingfield MJ. 1986. Pathogenicity of Leptographium procerum and L. terebrantis on Pinus strobus seedlings and established trees. European Journal of Forest Pathology 16: 299-308. 